\title{
What do we know about biomarkers in diabetic kidney disease?
}

\author{
Hanna Kwiendacz', Katarzyna Nabrdalik', Tomasz Stompór², Janusz Gumprecht ${ }^{1}$ \\ ${ }^{1}$ Department of Internal Medicine, Diabetology, and Nephrology, Faculty of Medical Sciences in Zabrze, \\ Medical University of Silesia, Katowice, Poland \\ ${ }^{2}$ Department of Nephrology, Hypertensiology, and Internal Diseases, University of Warmia and Mazury, Olsztyn, Poland
}

\begin{abstract}
Diabetic kidney disease (DKD) remains the leading cause of the end-stage renal disease (ESRD) and the most common reason for renal replacement therapy. Research has been carried out for years to find a marker that would enable early identification of people at risk of DKD occurrence, as well as people who will progress from DKD to ESRD. With regard to daily medical practice, the only existing prognostic biomarkers in DKD remain urine albumin-creatinine ratio based on the urinary assessment of albumin and creatinine, and estimated glomerular filtration rate - on the basis of serum creatinine concentration. The development of other biomarkers that would enable the identification of patients at risk of DKD, the stratification of the risk of progression to ESRD, as well as the creation of personalised therapy is currently of great interest. This article discusses selected studies in this field, which have been published in recent years. (Endokrynol Pol 2020; 71 (6): 545-550)
\end{abstract}

Key words: diabetic kidney disease; biomarker; UACR; eGFR

\section{Introduction}

Along with increasing prevalence of diabetes, the incidence of its vascular complications is rising. One such complication is diabetic kidney disease (DKD), which is now the leading cause of end-stage renal disease (ESRD). Another major problem is that DKD, like type 2 diabetes mellitus (T2DM) per se, remains asymptomatic for many years, which indicates the need for periodic screening to diagnose this complication. Importantly, the presence of DKD at any stage is associated with higher risk of death from cardiovascular causes than with progression to the next stage of chronic kidney disease (CKD), and cardiovascular events remain the most common cause of death in DKD patients [1-4]. Therefore, to reduce this risk, the therapeutic goal should not only be to prevent the onset of DKD but also to prevent its progression to ESRD [5]. For this reason, new biomarkers defined by the US Food and Drug Administration (FDA) as specific measurable features that are indicators of normal biological processes, pathological processes, or response to exposure or intervention are sought [6].

Classic prognostic biomarkers, used in everyday practice as an element of screening procedures for DKD, are urine albumin-creatinine ratio (UACR) and estimated glomerular filtration rate (eGFR) $[7,8]$. These are recommended by standards of management of patients with diabetes, both national [9] and international [10]. However, it transpires that these tests do not allow the detection of people at risk of developing kidney damage (before there is an increased excretion of albumin in the urine or a decrease in eGFR). Moreover, some critical voices refer to the role of albuminuria as a biomarker of DKD progression, because it is neither a sensitive nor specific indicator, and a significant number of people with kidney damage in the course of DKD are not affected by albuminuria. Nevertheless, if albuminuria occurs, it is a significant cardiovascular risk factor. In addition, albuminuria does not differentiate kidney damage induced by diabetes from other causes, which is especially important in T2DM. The development of prognostic biomarkers, other than eGFR and albuminuria, which could enable both the identification of patients at risk of DKD and the stratification of the risk of progression to ESRD and the creation of personalised therapy, is of great interest nowadays.

\section{Why do we need new prognostic biomarkers in DKD?}

Doctors face the difficult task of identifying patients at risk not only of the occurrence of DKD itself, but also of the progression to more advanced stages, and of 
identifying people whose disease progression will be rapid. For many years, the "albumin-centric" definition of DKD dominated, in which the occurrence of microalbuminuria was considered the beginning of DKD, and the progression of the disease was always the same, i.e. overt proteinuria, then the eGFR decreased, and finally ESRD occurred [11].

For many years, the most common marker of early kidney damage in DKD has been an increased UACR value, but this indicator has significant limitations. We currently know that the DKD phenotype is not as homogeneous as it seemed, and a significant percentage of patients progress to more advanced stages of DKD despite normal urine albumin excretion, both in type 1 diabetes (T1DM) and T2DM. The occurrence of albuminuria is also an event that occurs quite late in the natural history of DKD (its appearance is caused by already existing structural disorders, resulting in impaired functions of both the glomerulus and renal tubules). The urine albumin-creatinine ratio should therefore not be taken as an early failure indicator; on the contrary, one should look for biomarkers that predict the occurrence of albuminuria. Moreover, not all patients with elevated UACR values will have the disease progression to the end stage. Besides, a novelty is also that DKD may be characterised by rapid disease progression to ESRD, with the time between normal kidney function and its declining stage between 2 and 10 years [12]. For this reason, a biomarker that will reveal both the risk of DKD before significant kidney damage occurs and will allow the selection of people at risk of disease progression is needed.

\section{New prognostic biomarkers of DKD}

Because the type of diabetes is irrelevant for any of the biomarkers of DKD, there is no distinction between type 1 and 2 of the disease regarding this term. Studies assessing the possibility of using eGFR to estimate the risk of ESRD have shown that the progress of DKD can be predicted based on the observation of the initial course of the loss of glomerular filtration function (serial eGFR measurements over time) [13, 14]. Moreover, while remaining within the scope of the assessment of the glomerular filtration, it transpires that estimating it using cystatin $C$, and not serum creatinine, is a better method of predicting the risk of DKD course regardless of the type of diabetes [15]; therefore, cystatin C can be considered as a new predictive biomarker in DKD. Most research on new prognostic indicators of DKD development are based on single molecules that are candidate biomarkers or small collections (from a few to over a dozen) of such molecules that can be determined during one analysis. The selection of molecules (candidates) for research is based on the pathophysiological reasons for the development of DKD [16]. However, the opposite scenario is possible - for example, genome-wide association studies (GWAS) [17, 18] or proteomics studies identify genes or proteins significantly related to the occurrence of a given disease phenotype, and pathophysiological relationships between a given biomarker and development of the disease are unknown. Therefore, the search for biomarkers also broadens the knowledge of the pathophysiology of diseases, focusing the researchers' attention on explaining the relationship between the newly identified biomarker and the mechanism of disease development.

Regarding the early detection or prediction of DKD development, the most frequently studied molecules are inflammatory and fibrotic markers such as tumour necrosis factor 1 and 2 receptors (TNFR1 and TNFR2) $[19,20]$ or fibroblast growth factor 21 (FGF 21) [21], as well as biomarkers of myocardial damage, such as the $\mathrm{N}$-terminal pro-B-type natriuretic peptide (NT-proBNP) [22] or haemodynamic stress biomarkers, such as copeptin (a stable fragment of the pre-pro-vasopressin hormone that allow indirect testing of the concentration of this hormone) [23] and proteins indicating proximal urethral damage, i.e. kidney injury molecule 1 (KIM-1) and neutrophil gelatinase-associated lipocalin (NGAL) [24]. In recent years, the interest of researchers has also been attracted by such molecules as epidermal growth factor (EGF) [25-27], Klotho protein [28, 29], and TGF $\beta 1$ inhibitor, i.e. bone morphogenetic protein 7 (BMP-7), whose reduced concentration is associated with the progressive course of DKD [30]. EGF is a regulator of many metabolic processes. In a study from the Joslin Kidney Study of 1032 T2DM patients, decreased urine EGF concentration was associated with an increased risk of early progression of DKD [31]. The protective effect of EGF was even more pronounced when it was standardised against the monocyte chemotactic protein 1 (MCP-1) and assessed as an EGF/MCP-1 ratio [27]. Another assessed biomarker is the Klotho protein, which was originally identified as an anti-aging protein. Klotho protein is a co-receptor of fibroblast growth factor 23 (FGF23) and is mainly synthesised by the renal tubules [28]. It has been shown that decreased Klotho protein levels were associated with the risk of progressing DKD [32-35]. Another promising biomarker mentioned above is the TGF $\beta 1$ inhibitor, whose gene was identified in the latest GWAS study as potentially related to DKD [36]. It has been shown that people with lower BMP-7 levels had a higher risk of developing DKD [30].

In order to increase the strength of the scientific evidence and prove that it applies to the entire population of DM patients, the results of these studies require 
confirmation in larger patient populations. In addition to the studies on the biomarker candidate evaluation (in which the search is based on the hypothesis of the relationship of a specific molecule with the pathophysiological process), in recent years new research called "omics" studies has been carried out. This is a relatively new field in which very large samples of data are assessed by consortia, and they include genomics (i.e. genome research), epigenomics (i.e. the assessment of chemical modification of genetic material), transcriptomics (i.e. the evaluation of mRNA and miRNA), proteomics (i.e. the evaluation of proteins), metabolomics (i.e. the evaluation of metabolites), and lipidomics (i.e. the evaluation of lipids). Important elements of such research are information technology and mathematical and analytical systems [37]. The consortia dealing with DKD include the following: Risk Assessment and Progression of Diabetes (RHAPSODY), Surrogate markers for Micro-and Macro-vascular Hard Endpoints for Innovative Diabetes Tools (SUMMIT), and Biomarker Enterprise to Attack Diabetic Kidney Disease (BEAt-DKD) [38-40]. The SUMMIT consortium analysis revealed that two proteins, namely KIM-1 and $\beta 2$ microglobulin, were found to be important predictive biomarkers of rapid progress in eGFR decline [41]. Subsequent analysis took a step forward and allowed the simultaneous identification of large groups of potential markers of the risk of DKD progression derived from proteomic, metabolomic, and lipidomic analysis
$[42,43]$. The first of such "omics" studies designed to search for prognostic markers in DKD was conducted by the BEAt-DKD consortium [44], which assessed lipid and protein biomarkers and metabolic factors to predict the rate of eGFR reduction in the early stages of CKD in diabetic patients as an addition to clinical risk factors for DKD. It was shown that KIM-1 (and to a lesser extent - NTproBNP) influenced the dynamics of eGFR loss significantly, but further research in this area is necessary. In addition, it is worth mentioning the test assessing a panel of 273 proteins and peptides determined in urine using mass spectrometry, known as CKD273 (CKD classifier 273), which has been available since 2017 as a commercial test (http://mosaiques-diagnostic.de/mosaiquie-diagnostics). Its usefulness in the determination of the risk of DKD progression was confirmed in the PRIORITY trial (Proteomic Prediction and Renin Angiotensin Aldosterone System Inhibition Prevention Of Early Diabetic nephRopathy In TYpe 2 Diabetic Patients With Normoalbuminuria), the results of which were published in April 2020 [45]. The PRIORITY trial is also intended to help identifying patients best responding to renin-angiotensin-aldosterone system inhibition [46]. It seems that the CKD273 panel is today a tool that comes closest to the "proteomic biopsy" expected by many nephrologists (not to say - dreamed of).

New prognostic biomarkers are summarised in Table 1.

Table 1. New prognostic biomarkers for diabetic kidney disease (DKD) and their basic characteristics

\begin{tabular}{|c|c|c|}
\hline Biomarker & Pathophysiological role & Association with DKD \\
\hline $\begin{array}{l}\text { Tumour necrosis factor } 1 \\
\text { receptor (TNFR1) }\end{array}$ & $\begin{array}{l}\text { One of the major receptors for tumour necrosis factor- } \\
\text { alpha; can activate the transcription factor NF- } \kappa \text {, } \\
\text { mediates apoptosis and function as a regulator of } \\
\text { inflammation. }\end{array}$ & $\begin{array}{c}\text { Elevated serum TNFR1 concentration is associated } \\
\text { with increased risk of ESRD in T2DM }\end{array}$ \\
\hline $\begin{array}{l}\text { Tumour necrosis factor } 2 \\
\text { receptor (TNFR2) }\end{array}$ & $\begin{array}{l}\text { Together with TNFR1 forms a complex that mediates the } \\
\text { recruitment of anti-apoptosis proteins (c-IAP1 and c-IAP2) }\end{array}$ & $\begin{array}{l}\text { Elevated serum TNFR2 concentration is associated } \\
\text { with increased risk of end-stage renal disease T2DM }\end{array}$ \\
\hline $\begin{array}{l}\text { Fibroblast growth } \\
\text { factor } 21 \text { (FGF21) }\end{array}$ & $\begin{array}{l}\text { Stimulates glucose uptake in adipocytes, and this effect } \\
\text { is additive to the activity of insulin }\end{array}$ & $\begin{array}{c}\text { Serum FGF-21 concentration is positively associated } \\
\text { with UACR in T2DM patients }\end{array}$ \\
\hline $\begin{array}{l}\text { N-terminal pro-B-type } \\
\text { natriuretic peptide } \\
\text { (NT-proBNP) }\end{array}$ & $\begin{array}{c}\text { It is a biomarker of myocardial damage, used for diagnosis } \\
\text { of acute congestive heart failure and to establish its } \\
\text { prognosis }\end{array}$ & $\begin{array}{c}\text { NT-proBNP is associated with renal disease } \\
\text { progression }\end{array}$ \\
\hline Copeptin & $\begin{array}{l}\text { It is a stable fragment of the pre-pro-vasopressin } \\
\text { and a hemodynamic stress biomarker }\end{array}$ & $\begin{array}{c}\text { Copeptin concentration is associated with declining } \\
\text { eGFR in patients with DM }\end{array}$ \\
\hline $\begin{array}{l}\text { Kidney injury molecule-1 } \\
\text { (KIM-1) }\end{array}$ & $\begin{array}{l}\text { It is a good marker of active/ongoing tubular damage } \\
\text { but not tubular scarring }\end{array}$ & $\begin{array}{l}\text { Elevated concentration of KIM- } 1 \text { is associated } \\
\text { with a faster decline in eGFR }\end{array}$ \\
\hline $\begin{array}{l}\text { Neutrophil gelatinase- } \\
\text { associated lipocalin } \\
\text { (NGAL) }\end{array}$ & $\begin{array}{l}\text { It is produced as a response to tubular injury and therefore } \\
\text { is representative of the functioning tubular mass }\end{array}$ & $\begin{array}{l}\text { Elevated concentration of NGAL is associated } \\
\text { with a faster decline in eGFR }\end{array}$ \\
\hline $\begin{array}{l}\text { Epidermal growth factor } \\
\text { (EGF) }\end{array}$ & $\begin{array}{l}\text { It is a tubule-specific protein, which modulates tissue } \\
\text { response to injury in kidneys with tubulointerstitial } \\
\text { damage }\end{array}$ & $\begin{array}{l}\text { Its decreased urine concentration is associated } \\
\text { with an increased risk of early progression of DKD }\end{array}$ \\
\hline
\end{tabular}


Table 1. New prognostic biomarkers for diabetic kidney disease (DKD) and their basic characteristics

\begin{tabular}{lcc}
\hline Biomarker & Pathophysiological role & Association with DKD \\
\hline Klotho protein & $\begin{array}{c}\text { Originally defined as an anti-aging protein; it is a co-receptor } \\
\text { of FGF23 and is mainly synthesised by the renal tubules }\end{array}$ & $\begin{array}{c}\text { Its decreased concentration is associated with the risk } \\
\text { of DKD progression }\end{array}$ \\
\hline $\begin{array}{l}\text { Bone morphogenetic } \\
\text { protein 7 (BMP-7) }\end{array}$ & It is a natural antagonist to TGF- $\beta$ 1and has antifibrotic & $\begin{array}{c}\text { Its reduced concentration is associated with a higher } \\
\text { risk of developing and progressive course of DKD }\end{array}$ \\
\hline
\end{tabular}

NF- $\kappa$ B — nuclear factor kappa B; ESRD — end-stage renal disease; T2DM — type 2 diabetes mellitus; c-IAP — cellular inhibitor of apoptosis protein-1; UACR — urine albumin-creatinine ratio; FGF — fibroblast growth factor; NT-proBNP — N-terminal pro-B-type natriuretic peptide; eGFR — estimated glomerular filtration rat

\section{Extracellular vesicles - a new category of biomarkers in DKD}

Extracellular vesicles (EV) are spherical structures surrounded by the cell membrane, physiologically released by the cell - they exchange information between neighbouring or remote cells. They are secreted into the blood and most body fluids, including urine. Depending on the size and processes in which they are formed, they are divided into exosomes and microvesicles (MV). EV can be compared to a calling card in which a cell encapsulates a series of proteins, lipids, DNA, and RNA fragments, and by this means mediates intercellular signalling and communication. In various pathological processes, both the number of EV released by the cell and their content change. As mentioned above, one of the shortcomings of biomarkers is their low representativeness (we usually test one or several molecules). Taking this aspect into account, the information about what is happening in the cell based on the analysis of the MV content is much more complete because MVs contain numerous components, which are both proteins or peptides, as well as miRNA, mRNA, and lipids (information carriers are also membrane structures themselves). While the method of obtaining and isolating MVs is quite complicated, their content is more stable (the cell membrane protects, for example, proteins against proteolytic enzymes present in urine); they are also stable during long-term storage and over many repeated freeze-thaw cycles. All nephron cells can be the source of MV found in urine, with special attention being paid to MVs released by podocytes and proximal tubular cells.

Currently, the predictive value for the development of DKD is proven for a number of miRNA types, mRNA (mainly for the Wilms tumour protein 1 [WT1 protein], which plays a major regulatory role in podocyte homeostasis) and proteins (e.g. megalin C, WT1 protein itself, regucalcin, osteoprotegerin, aquaporins 2 and 5, and others) and the constellations of these components, enclosed inside the MV $[47,48]$.

\section{The effect of the "newer" antidiabetic agents on DKD biomarkers}

Recent years have brought a lot of data on nephroprotective effect of the new antidiabetic agents, like sodium-glucose transport protein 2 inhibitors (SGLT2i) or glucagon-like peptide 1 receptor agonists (GLP1-RA), but until now very limited data in humans are available regarding their impact on modern urinary biomarkers [49]. Some animal studies have demonstrated that both SGLT2i and GLP1-RA modify the expression of several cytokines or elements of oxidative stress or fibrosis pathways in renal tissue itself, but urine biomarkers seem not to have been analysed [50]. Nevertheless, in the nearest future we should expect several secondary analyses of both cardiovascular outcome trials and trials with pre-defined renal endpoints, which will report the impact of newer glucose-lowering drugs on urine biomarkers in patients participating in these landmark trials. As for today, such analyses seem to be largely limited to "classical" biomarkers, such as albuminuria [51].

\section{Conclusions}

Despite many completed and on-going studies of new prognostic biomarkers in the development and progression of DKD, only UACR and eGFR have been routinely used as DKD biomarkers for many years. It seems that due to the multifactorial background of DKD, (including both genetic and environmental factors), and despite the modern technological progress (both in terms of the development of new diagnostic methods and models of bioinformatics analysis), the introduction of new DKD prognostic biomarkers into everyday medical practice is not an easy task. However, it is certainly not impossible, and it is hoped that the results of the on-going research will provide new answers soon.

\section{References}

1. Livingstone SJ, Levin D, Looker HC, et al. Scottish Diabetes Research Network epidemiology group, Scottish Renal Registry. Estimated life expectancy in a Scottish cohort with type 1 diabetes, 2008-2010. 
JAMA. 2015; 313(1): 37-44, doi: 10.1001/jama.2014.16425, indexed in Pubmed: 25562264.

2. Livingstone SJ, Looker HC, Hothersall EJ, et al. Risk of cardiovascular disease and total mortality in adults with type 1 diabetes: Scottish registry linkage study. PLoS Med. 2012; 9(10): e1001321, doi: 10.1371/journal. pmed.1001321, indexed in Pubmed: 23055834.

3. Sharma P, McCullough K, Scotland G, et al. Does stage-3 chronic kidney disease matter?: A systematic literature review. Br J Gen Pract. 2010; 60(575): e266-e276, doi: 10.3399/bjgp10x502173.

4. Cypryk K, Małecki P. A review of cardiovascular outcome trials in type 2 diabetes. Endokrynol Pol. 2018; 69(4), doi: 10.5603/EP.2018.0053, indexed in Pubmed: 30209802.

5. Szczech LA, Stewart RC, Su HL, et al. Primary care detection of chronic kidney disease in adults with type-2 diabetes: the ADD-CKD Study (awareness, detection and drug therapy in type 2 diabetes and chronic kidney disease). PLoS One. 2014; 9(11): e110535, doi: 10.1371/journal. pone.0110535, indexed in Pubmed: 25427285.

6. FDA-NIH Biomarker Working Group. BEST (Biomarkers, EndpointS, and other Tools) Resource [Internet]. Silver Spring (MD): Food and Drug Administration (US); 2016. Co-published by National Institutes of Health (US), Bethesda (MD). https://www.ncbi.nlm.nih. gov/books/NBK326791/ (13.08.2020).

7. Mogensen CE. Microalbuminuria as a predictor of clinical diabetic nephropathy. Kidney Int. 1987; 31(2): 673-689, doi: 10.1038/ki.1987.50, indexed in Pubmed: 3550239.

8. Jones RH, Hayakawa H, Mackay JD, et al. Progression of diabetic nephropathy. Lancet. 1979; 1(8126): 1105-1106, doi: 10.1016/s0140-6736(79)91788-4, indexed in Pubmed: 86831.

9. Araszkiewicz A, Bandurska-Stankiewicz E, Budzyński A, et al. 2020 Guidelines on the management of diabetic patients. A position of Diabetes Poland. Clin Diab. 2020; 9(1): 1-101, doi: 10.5603/dk.2017.0001, indexed in Pubmed: 10.5603/DK.2020.0001.

10. American Diabetes Association. 11. Microvascular Complications and Foot Care. Standards of Medical Care in Diabetes - 2020. Diabetes Care. 2020; 43(Suppl 1): S135-S151, doi: 10.2337/dc20-S011, indexed in Pubmed: 31862754

11. Viberti GC, Jarrett RJ, Keen H. Microalbuminuria as prediction of nephropathy in diabetics. Lancet. 1982; 2(8298): 611, doi: 10.1016/s0140-6736(82)90688-2, indexed in Pubmed: 6125757.

12. Skupien J, Warram JH, Smiles AM, et al. Patterns of Estimated Glomerular Filtration Rate Decline Leading to End-Stage Renal Disease in Type Diabetes. Diabetes Care. 2016; 39(12): 2262-2269, doi: 10.2337/dc16-0950, indexed in Pubmed: 27647852.

13. Oshima M, Toyama T, Haneda M, et al. Research Group of Diabetic Nephropathy, Ministry of Health, Labour, and Welfare of Japan. Estimated glomerular filtration rate decline and risk of end-stage renal disease in type 2 diabetes. PLoS One. 2018; 13(8): e0201535, doi: 10.1371/journal pone.0201535, indexed in Pubmed: 30071057.

14. Skupien J, Warram JH, Smiles AM, et al. The early decline in renal function in patients with type 1 diabetes and proteinuria predicts the risk of end-stage renal disease. Kidney Int. 2012; 82(5): 589-597, doi: 10.1038/ki.2012.189, indexed in Pubmed: 22622493.

15. Krolewski AS, Warram JH, Forsblom C, et al. Serum concentration of cystatin $\mathrm{C}$ and risk of end-stage renal disease in diabetes. Diabetes Care. 2012; 35(11): 2311-2316, doi: 10.2337/dc11-2220, indexed in Pubmed: 22851596.

16. Colhoun HM, Marcovecchio ML. Biomarkers of diabetic kidney disease. Diabetologia. 2018; 61(5): 996-1011, doi: 10.1007/s00125-018-4567-5, indexed in Pubmed: 29520581.

17. Jendrzejewski JP, Sworczak K, Comiskey DF, et al. Clinical implications of GWAS variants associated with differentiated thyroid cancer. Endokrynol Pol. 2019; 70(5): 423-429, doi: 10.5603/EP.a2019.0027, indexed in Pubmed: 31681970.

18. Kwiendacz H, Nabrdalik K, Adamczyk P, et al. Association of single nucleotide polymorphism (rs741301) of the ELMO1 gene with diabetic kidney disease in Polish patients with type 2 diabetes: a pilot study. Endokrynol Pol. 2020; 71(1): 66-72, doi: 10.5603/EP.a2019.0066, indexed in Pubmed: 31909452

19. Pavkov ME, Weil EJ, Fufaa GD, et al. Tumor necrosis factor receptors 1 and 2 are associated with early glomerular lesions in type 2 diabetes. Kidney Int. 2016;89:226-234. Kidney Int. 2016; 90(3): 709, doi: 10.1016/j. kint.2016.06.002, indexed in Pubmed: 27521121.

20. Niewczas MA, Gohda T, Skupien J, et al. Circulating TNF receptors 1 and 2 predict ESRD in type 2 diabetes. J Am Soc Nephrol. 2012; 23(3) 507-515, doi: 10.1681/ASN.2011060627, indexed in Pubmed: 22266663.

21. Jian WX, Peng WH, Jin J, et al. Association between serum fibroblast growth factor 21 and diabetic nephropathy. Metabolism. 2012; 61(6): 853-859, doi: 10.1016/j.metabol.2011.10.012, indexed in Pubmed: 22136913.

22. Bidadkosh A, Lambooy SPH, Heerspink HJ, et al. Predictive Properties of Biomarkers GDF-15, NTproBNP, and hs-TnT for Morbidity and Mortality in Patients With Type 2 Diabetes With Nephropathy. Diabetes Care. 2017 40(6): 784-792, doi: 10.2337/dc16-2175, indexed in Pubmed: 28341782.

23. Boertien WE, Riphagen IJ, Drion I, et al. Copeptin, a surrogate marker for arginine vasopressin, is associated with declining glomerular filtration in patients with diabetes mellitus (ZODIAC-33). Diabetologia. 2013; 56(8): 1680-1688, doi: 10.1007/s00125-013-2922-0, indexed in Pubmed: 23624546.

24. Nielsen SE, Reinhard H, Zdunek D, et al. Tubular markers are associated with decline in kidney function in proteinuric type 2 diabetic patients. Diabetes Res Clin Pract. 2012; 97(1): 71-76, doi: 10.1016/j.diabres.2012.02.007, indexed in Pubmed: 22402306.

25. Wu L, Li XQ, Chang DY, et al. Associations of urinary epidermal growth factor and monocyte chemotactic protein-1 with kidney involvemen in patients with diabetic kidney disease. Nephrol Dial Transplant. 2020 35(2): 291-297, doi: 10.1093/ndt/gfy314, indexed in Pubmed: 30357416.

26. Li B, Zhang Y, Wang F, et al. Urinary epidermal growth factor as a prognostic marker for the progression of Alport syndrome in children. Pediatr Nephrol. 2018; 33(10): 1731-1739, doi: 10.1007/s00467-018-3988-1, indexed in Pubmed: 29948307.

27. Isaka Y. Epidermal growth factor as a prognostic biomarker in chronic kidney diseases. Ann Transl Med. 2016; 4(Suppl 1): S62, doi: 10.21037/atm.2016.10.64, indexed in Pubmed: 27868030.

28. Kurosu H, Yamamoto M, Clark JD, et al. Suppression of aging in mice by the hormone Klotho. Science. 2005; 309(5742): 1829-1833, doi: 10.1126/science.1112766, indexed in Pubmed: 16123266.

29. Flotyńska J, Uruska A, Araszkiewicz A, et al. Klotho protein function among patients with type 1 diabetes. Endokrynol Pol. 2018; 69(6): 696-704, doi: 10.5603/EP.a2018.0070, indexed in Pubmed: 30620382

30. Wong MG, Perkovic V, Woodward M, et al. Circulating bone morphogenetic protein- 7 and transforming growth factor- $\beta 1$ are better predictors of renal end points in patients with type 2 diabetes mellitus. Kidney Int. 2013; 83(2): 278-284, doi: 10.1038/ki.2012.383, indexed in Pubmed: 23235570.

31. Nowak N, Skupien J, Smiles AM, et al. Markers of early progressive renal decline in type 2 diabetes suggest different implications for etiological studies and prognostic tests development. Kidney Int. 2018; 93(5): 1198-1206, doi: 10.1016/j.kint.2017.11.024, indexed in Pubmed: 29398132.

32. Drew DA, Katz R, Kritchevsky S, et al. Association between Soluble Klotho and Change in Kidney Function: The Health Aging and Body Composition Study. J Am Soc Nephrol. 2017; 28(6): 1859-1866, doi: 10.1681/ASN.2016080828, indexed in Pubmed: 28104822.

33. Liu OF, Yu LX, Feng JH, et al. The Prognostic Role of Klotho in Patients with Chronic Kidney Disease: A Systematic Review and Meta-analysis. Dis Markers. 2019; 2019: 6468729, doi: 10.1155/2019/6468729, indexed in Pubmed: 31275449

34. Kim SS, Song SH, Kim InJ, et al. Decreased plasma -Klotho predict progression of nephropathy with type 2 diabetic patients. J Diabetes Complications. 2016; 30(5): 887-892, doi: 10.1016/j.jdiacomp.2016.03.006, indexed in Pubmed: 27037042

35. Fountoulakis N, Maltese G, Gnudi L, et al. Reduced Levels of Anti-Ageing Hormone Klotho Predict Renal Function Decline in Type 2 Diabetes. J Clin Endocrinol Metab. 2018; 103(5): 2026-2032, doi: 10.1210/jc.2018-00004, indexed in Pubmed: 29509906.

36. Salem RM, Todd JN, Sandholm N, et al. SUMMIT Consortium, DCCT/EDIC Research Group, GENIE Consortium. Genome-Wide Association Study of Diabetic Kidney Disease Highlights Biology Involved in Glomerular Basement Membrane Collagen. J Am Soc Nephrol. 2019; 30(10): 2000-2016, doi: 10.1681/ASN.2019030218, indexed in Pubmed: 31537649.

37. Tebani A, Afonso C, Marret S, et al. Omics-Based Strategies in Precision Medicine: Toward a Paradigm Shift in Inborn Errors of Metabolism Investigations. Int J Mol Sci. 2016; 17(9), doi: 10.3390/ijms17091555, indexed in Pubmed: 27649151

38. Mayer G, Heerspink HJL, Aschauer C, et al. SYSKID Consortium Systems Biology-Derived Biomarkers to Predict Progression of Renal Function Decline in Type 2 Diabetes. Diabetes Care. 2017; 40(3): 391-397, doi: 10.2337/dc16-2202, indexed in Pubmed: 28077457.

39. Ahlqvist E, Storm P, Käräjämäki A, et al. Novel subgroups of adult-onset diabetes and their association with outcomes: a data-driven cluster analysis of six variables. Lancet Diabetes Endocrinol. 2018; 6(5): 361-369, doi: 10.1016/S2213-8587(18)30051-2, indexed in Pubmed: 29503172.

40. van Zuydam NR, Ahlqvist E, Sandholm N, et al. Finnish Diabetic Nephropathy Study (FinnDiane), Hong Kong Diabetes Registry Theme-based Research Scheme Project Group, Warren 3 and Genetics of Kidneys in Diabetes (GoKinD) Study Group, GENIE (GEnetics of Nephropathy an International Effort) Consortium, Diabetes Control and Complications Trial (DCCT)/Epidemiology of Diabetes Interventions and Complications (EDIC) Research Group, SUrrogate markers for Micro- and Macrovascular hard endpoints for Innovative diabetes Tools (SUMMIT) Consortium. A Genome-Wide Association Study of Diabetic Kidney Disease in Subjects With Type 2 Diabetes. Diabetes. 2018 67(7): 1414-1427, doi: 10.2337/db17-0914, indexed in Pubmed: 29703844 
41. Colombo M, Looker HC, Farran B, et al. SUMMIT Investigators. Serum kidney injury molecule 1 and $\beta$-microglobulin perform as well as larger biomarker panels for prediction of rapid decline in renal function in type 2 diabetes. Diabetologia. 2019; 62(1): 156-168, doi: 10.1007/s00125-018-4741-9, indexed in Pubmed: 30288572.

42. Mayer P, Mayer B, Mayer G. Systems biology: building a useful model from multiple markers and profiles. Nephrol Dial Transplant. 2012; 27(11): 3995-4002, doi: 10.1093/ndt/gfs489, indexed in Pubmed: 23144070.

43. Afshinnia F, Rajendiran TM, Wernisch S, et al. Lipidomic Signature of Progression of Chronic Kidney Disease in the Chronic Renal Insufficiency Cohort. Kidney Int Rep. 2016; 1(4): 256-268, doi: 10.1016/j. ekir.2016.08.007, indexed in Pubmed: 28451650.

44. Kammer M, Heinzel A, Willency JA, et al. BEAt-DKD Consortium. Integrative analysis of prognostic biomarkers derived from multiomics panels helps discrimination of chronic kidney disease trajectories in people with type 2 diabetes. Kidney Int. 2019; 96(6): 1381-1388, doi: 10.1016/j. kint.2019.07.025, indexed in Pubmed: 31679767.

45. Tofte N, Lindhardt M, Adamova K, et al. PRIORITY investigators. Early detection of diabetic kidney disease by urinary proteomics and subsequent intervention with spironolactone to delay progression (PRIORITY): a prospective observational study and embedded randomised placebo-controlled trial. Lancet Diabetes Endocrinol. 2020; 8(4): 301-312, doi: 10.1016/S2213-8587(20)30026-7, indexed in Pubmed: 32135136.
46. Heerspink HJL, Stefansson BV, Chertow GM, et al. DAPA-CKD Investigators. Rationale and protocol of the Dapagliflozin And Prevention of Adverse outcomes in Chronic Kidney Disease (DAPA-CKD) randomized controlled trial. Nephrol Dial Transplant. 2020; 35(2): 274-282, doi: 10.1093/ndt/gfz290, indexed in Pubmed: 32030417.

47. Sinha N, Kumar V, Puri V, et al. Urinary exosomes: Potential biomarkers for diabetic nephropathy. Nephrology (Carlton). 2020 [Epub ahead of print], doi: 10.1111/nep.13720, indexed in Pubmed: 32323449.

48. Lu Y, Liu D, Feng Qi, et al. Diabetic Nephropathy: Perspective on Extracellular Vesicles. Front Immunol. 2020; 11: 943, doi: 10.3389/fimmu.2020.00943, indexed in Pubmed: 32582146.

49. Tonneijck L, Muskiet MHA, Blijdorp CJ, et al. Renal tubular effects of prolonged therapy with the GLP-1 receptor agonist lixisenatide in patients with type 2 diabetes mellitus. Am J Physiol Renal Physiol. 2019; 316(2): F231-F240, doi: 10.1152/ajprenal.00432.2018, indexed in Pubmed: 30353743.

50. Ninčević V, Omanović Kolarić T, Roguljić H, et al. Renal Benefits of SGLT 2 Inhibitors and GLP-1 Receptor Agonists: Evidence Supporting a Paradigm Shift in the Medical Management of Type 2 Diabetes. Int J Mol Sci. 2019; 20(23), doi: 10.3390/ijms20235831, indexed in Pubmed: 31757028.

51. Scheen AJ. Effects of glucose-lowering agents on surrogate endpoints and hard clinical renal outcomes in patients with type 2 diabetes. Diabetes Metab. 2019; 45(2): 110-121, doi: 10.1016/j.diabet.2018.10.003, indexed in Pubmed: 30477733. 